\title{
Quality Enhancing Parameters of Learning Management Systems: An E-Learning Perspective in India
}

Javed Mohammad, Fayzieva Muyassarzoda Khancharovna

To Link this Article: http://dx.doi.org/10.6007/IJARBSS/v11-i4/9680

DOI:10.6007/IJARBSS/v11-i4/9680

Received: 14 February 2021, Revised: 16 March 2021, Accepted: 31 March 2021

Published Online: 19 April 2021

In-Text Citation: (Mohammad \& Khancharovna, 2021)

To Cite this Article: Mohammad, J., \& Khancharovna, F. M. (2021). Quality Enhancing Parameters of Learning Management Systems: An E-Learning Perspective in India. International Journal of Academic Research in Business and Social Sciences, 11(4), 392-411.

\section{Copyright: (c) 2021 The Author(s)}

Published by Human Resource Management Academic Research Society (www.hrmars.com)

This article is published under the Creative Commons Attribution (CC BY 4.0) license. Anyone may reproduce, distribute, translate and create derivative works of this article (for both commercial and non-commercial purposes), subject to full attribution to the original publication and authors. The full terms of this license may be seen at: http://creativecommons.org/licences/by/4.0/legalcode

Vol. 11, No. 4, 2021, Pg. 392 - 411

Full Terms \& Conditions of access and use can be found at http://hrmars.com/index.php/pages/detail/publication-ethics 


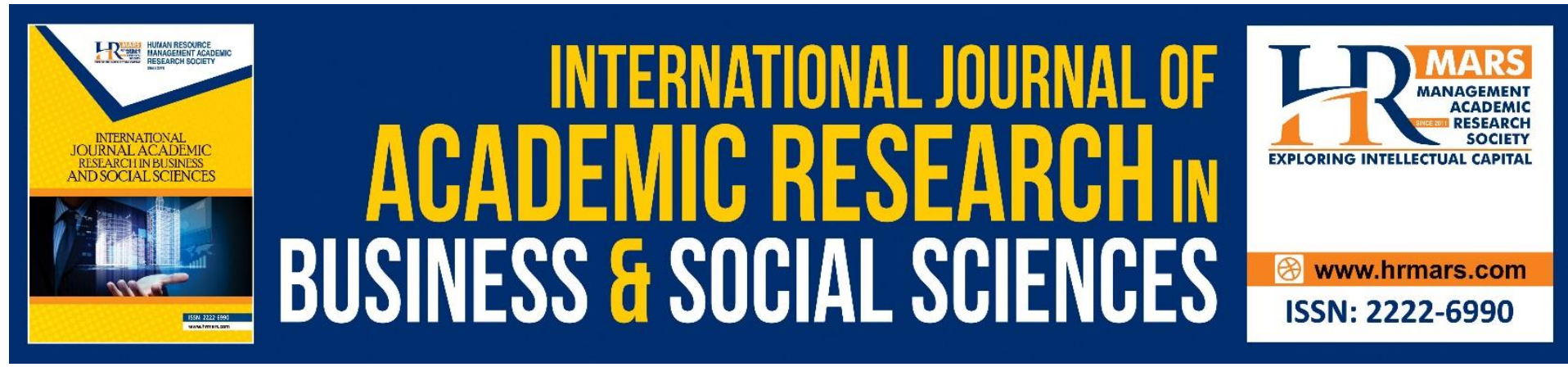

\title{
Quality Enhancing Parameters of Learning Management Systems: An E-Learning Perspective in India
}

\author{
${ }^{1}$ Javed Mohammad, ${ }^{2}$ Fayzieva Muyassarzoda Khancharovna \\ ${ }^{1}$ Doctoral Candidate, Binary University, Malaysia, ${ }^{2} \mathrm{MBA}$ student, Binary Graduate School, \\ Tashkent Institute of Finance, Uzbekistan
}

\begin{abstract}
E-learning through learning management systems (LMS) provides the advantages of effective learning content, higher information consistency, and easier update of content. Understanding of parameters that affect the effectiveness of learning management systems is crucial if academic institutions are to introduce e-learning through LMS. The objectives of the study are: (i) To identify the parameters that enhance the quality of learning management systems (ii) To analyze the quality enhancing parameters of LMS (iii) To suggest measures to overcome the problems if any associated with the learning management systems for faculty development programme. The study employs a descriptive research method. The primary data was collected using a self- designed questionnaire using google forms facility from 200 faculty members teaching at public and private colleges in Hyderabad, India. Initial refinement of the questionnaire was done through a pilot study with 30 responses. Data gathered were analyzed using SPSS Statistics 25 . Basic statistics analysis was done to describe the characteristic of the frequency, percentage, mean, variance, and standard deviation. Nonparametric test such as Mann-Whitney U-test was used to test the significant difference between the two groups of faculty members i.e., those working at private and public colleges and also gender wise variations. For testing hypotheses, one sample t- test was used. The findings from the study are: (i) the hypotheses tested have established that the quality parameter values are significantly higher than their corresponding weighted mean scores. (ii) The quality parameter "propriety" does not get influenced by gender. (iii) Quality parameters are not influenced by the type of institution. The study also makes recommendations for faculty members, students, and LMS developers aiming at contributing a milestone in enhancing the quality of learning management systems offering e-learning.
\end{abstract}

Keywords: LMS, e-Learning, Parameters of Quality, Hyderabad

\section{Introduction}

In the 21st century, the information and communication technology explosion upsurges the uses of digital devices for many purposes in the world of work and in formal and nonformal education (Kumar et al., 2018). In the current pandemic, the Learning Management Systems (LMS) have been thrown into the spotlight. Digital learning has rapidly gone mainstream and this huge trend will upend current education practices, models, and 
processes into the future. Social distancing and more time at home has given employees more time to think about their own learning and interests for upskilling.

\section{E-Learning}

E-Learning is the use of technology to deliver and design content to support learning in an Internet-enabled environment. It involves the convergence of technology, the Internet and learning. The components of e-learning comprise of content delivery in different formats, a team of trainers, learners and content developers and managing the learning experience. $\mathrm{E}-$ learning refers to the use of Internet technologies to deliver a broad array of learning modes that enhance learners' knowledge and performance (Ruiz et al., 2006). E-learning is the new wave in learning strategy. Through innovative use of modern technology, e-learning not only revolutionizes education and makes it more accessible, it also brings formidable challenges for instructors and learners (Hossain et al., 2018; Liaw et al., 2007). E- learning providers should develop a long-term strategy to improve the usability and quality of and add value to the service to maintain or enhance users' loyalties to the service (Chiu et al., 2005). E-Learning is a broader approach to learning that offers new prospects for learning and teaching in many fields of education far from the traditional classroom environment (Rodrigues et al., 2019). Tools used to support e-learning cover a wide range of different applications. They include discussion forums, chat, file sharing, video conferences, shared whiteboards, e-portfolios, weblogs and wikis. Such tools can be used to support different activities involved in the learning process. It is possible to integrate different tools in a single stand-alone system, a learning management system, also called virtual learning environments or e-learning systems (such systems include Blackboard, WebCT, Moodle).

The online education market in India was USD 247 million in 2016 with approximately 1.57 million paid users. Table 1.1 shows category-wise split of online education market in India (2016). Reskilling and online certification courses is the largest category in the Indian online education industry for skill development/enhancement (A KPMG in India-Google Report).

Table 1.1: Category-wise split of online education market in India (2016)

\begin{tabular}{llc}
\hline Online Education Market & USD (in millions) & No. of paid users (in thousands) \\
\hline Primary \& secondary supplemental education & 73 & 467 \\
Test preparation & 43 & 196 \\
Reskilling and online certifications & 93 & 499 \\
Higher education & 33 & 55 \\
Language and casual learning & 5 & 353 \\
\hline Total & 247 & 1570 \\
\hline
\end{tabular}

Source: Defining India's Internet, A KPMG in India-Google Report (April, 2017)

Table 1.2 shows projected category-wise split of online education market in India (2016 to 2021). 
Table 1.2: Category-wise split of online education market in India (2016 - 2021).

\begin{tabular}{|c|c|c|}
\hline Online Education Market & s) 2016 & $\begin{array}{l}\text { USD } \\
\text { (in millions) 2021P }\end{array}$ \\
\hline Primary \& secondary supplemental education & 73 & 773 \\
\hline Test preparation & 43 & 515 \\
\hline Reskilling and online certifications & 93 & 463 \\
\hline Higher education & 33 & 184 \\
\hline Language and casual learning & 5 & 29 \\
\hline Total & 247 & 1964 \\
\hline
\end{tabular}

Source: Defining India's Internet, A KPMG in India-Google Report (April,2017)

The online education market size in India has the potential to grow by USD 14.33 billion during 2020-2024, and the market's growth momentum will accelerate during the forecast period because of the steady increase in year-over- year growth (Technavio - Market Research Company).

\section{Online Faculty Induction Program}

The COVID-19 pandemic has dramatically changed education, with the distinctive need for e-learning and continuance of teaching-learning over remote and digital platforms (Hossain et al., 2020). The incorporation of information communication technology in education has already been on a high growth even before the pandemic. However, the sudden closure of educational institutions in many parts of the world has brought a certain urgency to adopt online teaching-learning strategies, which are likely to continue even post- COVID-19. Hence, the teaching community needs to evolve, more than ever, an innovative approach to equip themselves with the skills necessary for creating a holistic learning environment in this unprecedented context. In the contemporary world of modern education and knowledge, a teacher is not only a source of knowledge-creation but also the instrument required to sharpen the intellect of students. Education has changed over time to meet the progressive world. The education system has been reconstructing its focal variables, namely teaching, learning, institution, and knowledge.

Teaching and learning have shifted to create a phenomenological space, where the symbiotic relationship between the teacher and the student blossoms at a level that goes beyond mere cognition and thought. It transcends to explore the meaning of life, invoking the true inner calling and creating an environment for creative expression and experimentation. Likewise, terms like institution and knowledge now seek to establish systems of learning beyond the four walls of buildings, encompassing more than physical infrastructure, and information gathering and processing. Systems that ignite the drive to address the problems of the society create collaborative learning, attitude to acquire futuristic skills and an orientation to become self-reliant. Essentially, this amounts to redefine the time and space of education, respectively, from time spent in covering the syllabus and physical infrastructure to create an environment. This means expanding and broadening the cognitive faculty of students and empowering them to conceptualize phenomena for applications for the greater good of society. In this context, space means the combined mental landscape of the teacher and the taught, which is governed by the canons of inquisitiveness, enquiry, critical thinking, and nonconventional problem-solving. The traditional set-up of a classroom needs to be 
deconstructed and redesigned to help students adjust to the present-day requirements of multi-dimensionality, that is, not only being prompt to the socio-political and economic shifts but to pursue ones' inner calling. The exchange and interaction of ideas, thoughts, and concepts should stem from critical thinking. Innovative approaches, both for teaching and evaluation, should be adopted in addition to imparting immense value to the skill development and understanding of the ever-changing dynamics between the local and the global. However, this need of the hour to create skilled and professionally competent human resources can only be accomplished through equipping a teacher with the role that will enable students to develop their critical and analytical skills. These skills will further empower them to question and know. Hence faculty development training for upskilling is very important.

\section{Learning Management System (LMS)}

One approach to e-learning is the use of LMS. All LMS are not alike, and they can be used in different ways. However, a common idea behind LMS is that e-learning is organized and managed within an integrated system. Different tools are integrated in a single system which offers all necessary tools to run and manage an e-learning course. All learning activities and materials in a course are organized and managed by and within the system. LMS typically offer discussion forums, file sharing, management of assignments, lesson plans, syllabus, chat, etc. Figure 1.1 shows the structure of learning management system (LMS).

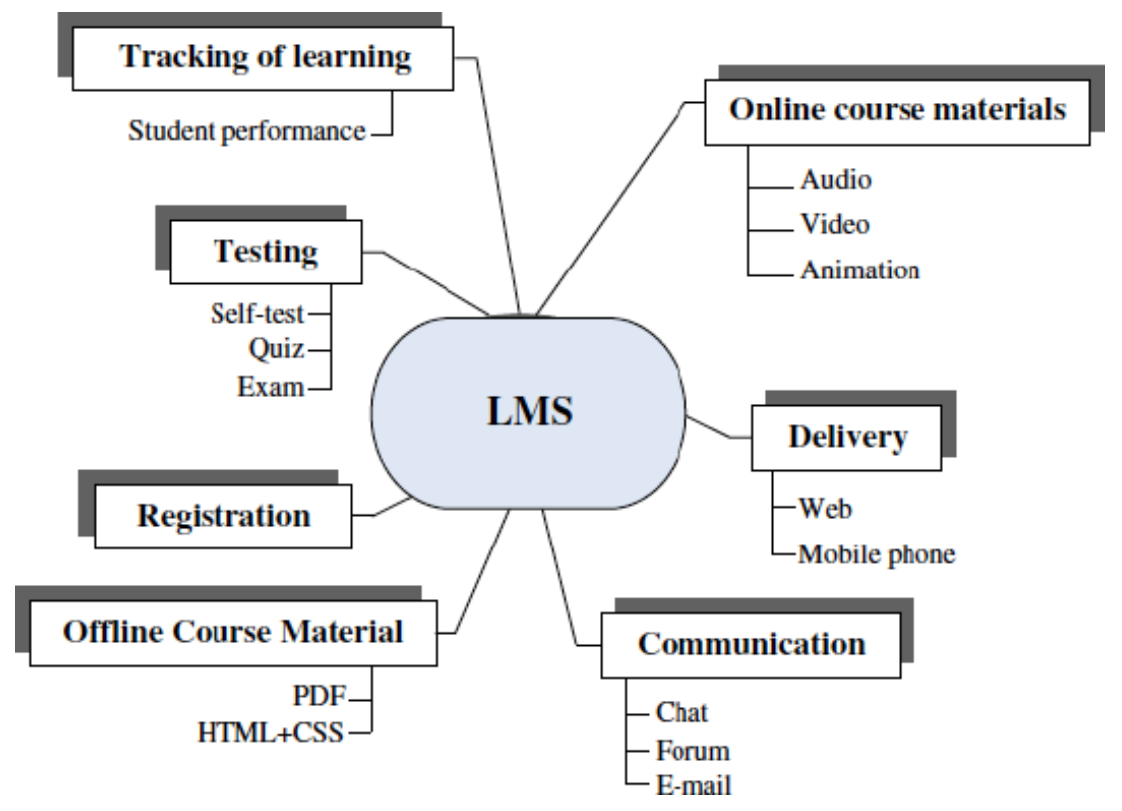

Figure 1.1: Structure of the Learning Management System (LMS)

A learning Management System is a web based or cloud based software program which assist in teaching learning process and helps in effective delivery of instruction, training and development program The Learning Management System facilitates instructors, learners and administrators to use and access of services and is beyond the restriction of time and place in teaching and learning process. Technically defined term for a learning management system is as: "A Learning Management System is a software application for the administration, documentation, tracking, reporting and delivering by e-learning education courses or training programs" (Ryan, 2009).

Learning Management System has two specifications which is largely affected the users: 
1. LMS usability lies in the specified needs of an individual or an organization. It means may be an LMS could be useful and very effective for a university or academic purpose but it does not mean that it will suit to the industries as well

2. Technically well-groomed assistant for the continuous support. Technical support makes us able to tackle any pitfalls or other issues which are hindering the best delivery of Learning Management System

Research on using LMSs and their impact on teaching and learning reports both positive and negative findings. In addition, many researchers highlight that LMSs have not always been used by faculty members to their fullest capability (Dahlstrom et al, 2014; Morgan, 2003; Bhattacharjee et al., 2019). In fact, faculty use LMSs in many ways, from a simple tool for communication and managing course materials and information to complex environments that enhance interactive teaching and learning (Polas et al., 2019; Chang, 2008; Heirdsfield et al., 2011; Klobas \& McGill, 2010; Lonn \& Teasley, 2009). An LMS offers a wide range of functionalities and tools to support teaching and learning. It not only delivers contents but also looks after administration, registration, tracking, skills gap analysis and reporting (Gilhooly, 2001). The effectiveness of the LMS is important aspect as it will aid the learners in making their learning process smoother. Often times complaints are heard from both instructors and students that they could not access the LMS due to connectivity problems or the fact that they needed to maneuver themselves to get to know the system better. More often than not, the platform needs to be user-friendly. Not only that, according to Cavus et.al (2007) the LMS will be more effective if there are advanced built-in collaborative tools, as they help the process of online learning become more effective than the existing LMS system in most universities. However, whether or not the LMS tool is useful, it still depends on the way the tool is used in a given course and if the tool aids the user to achieve the desired course outcomes. Students will need to know how to use the system to enhance their learning practices. The lack of knowledge and interest in utilizing the system among students can also make the LMS become less effective. The instructor henceforth plays a vital role in motivating the students to access it and make it interactive. Hence the objective of this paper is to analyze the parameters that enhance the quality of learning management system offering faculty development programs.

\section{Problem Statement}

E-Learning faces a challenge in terms of enhancing the quality of the learning management systems. Most of the learning management systems are application oriented and are not document oriented (researcher's opinion). The application-oriented systems may result in complex development of the LMS design. The e-learning framework lacks in meeting the quality parameters that are required by the end users. This study attempted to identify and analyze the parameters that constitute to enhance the overall quality of the LMS.

\section{Limitations of The Study}

- The study is limited to learning management systems that offer faculty development training programs to college faculties in Hyderabad, India.

- Samples have been drawn from public and private colleges that offer business management/business administration courses affiliated to Osmania University, Hyderabad, India. 


\section{Literature Review}

In a study by Gautreau (2011), the researcher looked at motivational and demographic factors that impacted a faculty member's decision to adopt the use of an LMS. One of the questions focused on the participants' demographics and the other question looked at intrinsic and extrinsic motivation factors to use an LMS. The results of the study concluded that age and gender were not significant factors in the faculty members' decision to use LMS, but tenure status, level of experience with a LMS and computer experiences were significant at $p<0.05$.

The results of the Little-Wiles, et al. (2012) study of faculty perceptions and use of an LMS in a higher education institution illustrated how the LMS features were being used in the classroom. The LMS features mentioned in the study are similar to the most popular LMS features identified by the faculty participants of this study. The LMS not only delivers online content put provides faculty an opportunity to fully engage the student in the topic.

Al-Busaidi and Al-Shihi (2012), this study examined the key factors that influence the instructors' satisfaction of LMS in blended learning, and how this satisfaction is related to their intention to continuously use LMS in blended learning and purely for distance education. The findings indicated that computer anxiety, personal innovativeness, system quality, information quality, management support, incentives policy and training are key factors to instructors' satisfaction of LMS in blended learning.

Hasan and Abuelrub (2011); Bashir et al (2020) aim at assessing quality of website, irrespective of the various types of services offered by the site. The method proposed by them concentrates on four dimensions of quality such as content quality, organization quality, design quality and user-friendly quality. These dimensions can be applied by any web developer and designer to design a quality web site. It is assistive for the researchers for improving the quality of web site to develop the theoretical knowledge, measurable and comprehensive framework.

Fard, Tafreshi et al. (2014) conducted a study to indicate the factors that influence the successes of e-learning systems. The study uses fuzzy TOPSIS technique as a new method to evaluate e-learning systems. The results show that system quality, information quality, service quality have the most positive impact on learners understanding of e-learning. Also, Alshamsi, et al., (2020) mentioned that the system quality is very important factor in relation to the service quality, information quality and learning community.

Mustafa, M. (2013) conducted a research was performed to focus on the system quality concept and explores usability, accessibility, reliability, and stability dimensions to evaluate the effect of these dimensions on e-learning system efficiency. The results show that usability factor was found as important dimension that affects the system quality and also the system quality is the main factor that increase or decrease the efficiency of LMS.

Jayakumar \& Banbehari (2014); Polas et al (2020) carried out a study to contribute on developing website quality assessment model for website's quality evaluation depending four quality parameters such as accuracy, feasibility, utility and propriety. The work analyzed the system quality of an existing e-learning site and obtained the feedback of the users where the preliminary assessment phase and the criterion-based analysis of each parameter is made. Then the evaluation process has been accomplished with two phases of evaluation: preliminary assessment phase and evaluation results analysis phase. With the suggestions obtained from the assessment process, a new improved e- learning environment is developed to satisfy the users with their best quality of content and design. 


\section{Research Questions}

The study is guided by the following research questions:

1. Is there any significant difference between the parameters of quality of learning management system and their corresponding weighted mean score?

2. Is there any significant difference between the responses of male and female faculties with respect to parameters of quality of learning management systems?

3. Is there any significant difference between the responses of private and public college faculties with respect to parameters of quality of learning management systems?

\section{Objectives}

The objectives of the study are:

1. To identify the parameters of that enhance the quality of learning management systems

2. To analyze the quality enhancing parameters of LMS

3. To suggest measures to overcome the problems if any associated with the learning management system for faculty development programme.

\section{Hypotheses}

The paper also outlines the following hypotheses which are congruent to the research questions and objective of the study. Demographic factors such as gender, type of college whether private or public and the act as the independent variable (IV) and faculty opinion with respect to quality parameters (accuracy, feasibility, utility and propriety) acts as the dependent variable (DV).

1. $\mathrm{H}_{01}$ : There is no significant difference between the parameters of quality of LMS and their corresponding weighted mean score.

2. $\mathrm{H}_{02}$ : There is no significant difference in the responses of male and female faculties with respect to the parameters of quality of LMS.

3. $\mathrm{H}_{03}$ : There is no significant difference in the responses of faculties working at public and private colleges with respect to quality parameters of LMS.

\section{Research Methodology}

\subsection{Method of Research}

This study utilized a descriptive research method to address the issues of the learning management systems in enhancing the quality. The learning management systems offering faculty development programs were identified through discussion with experts. The study used the survey method using a google form questionnaire comprising a number of statements to collect data from the respondents - public and private college faculties. Discussion with technical persons and focus group technique were employed to identify the parameters of quality and to develop the statements contained in the questionnaire. Initial refinement of the questionnaire was taken up through a pilot study and the final validation of the questionnaire was done using focus group technique.

\section{Population}

The population of the study comprised faculties teaching at private and public business colleges affiliated to Osmania University in Hyderabad, India. 20 colleges that offered faculty development training through learning management system during the lockdown period 
were considered to collect the data. The choice of colleges was purposive based on the ease of access for the researcher to meet the technical persons and focus group members to identify the parameters of quality and to develop the statements contained in the questionnaire.

\section{Sample}

The population size in the study is 400 faculties working at 40 colleges in Hyderabad who attended the faculty development program through LMS. According to Slovin's formula (random sampling technique formula), the sample size for $95 \%$ confidence level is

$$
\begin{aligned}
& n=400=200 \\
& (1+400 \times 0.05 \times 0.05)
\end{aligned}
$$

This sample size of 200 faculties was considered to be representative of the whole population in terms of providing their opinions regarding the quality of learning management systems.

\section{Instrument Used for Data Collection}

Data is gathered using google form questionnaire and were analyzed using a SPSS Statistics 25. A survey instrument containing thirty-six items was developed. The 21 statements in the instruments measure the underlying constructs, namely, accuracy (measured using 8 items), feasibility (measured using 5 items), utility (measured using 4 items) and propriety (measured using 4 items). The distribution of statements among the main factors is presented in Table 1.3 .

Table 1.3: Number of statements in the questionnaire

\begin{tabular}{ccc}
\hline Main Factors & $\begin{array}{c}\text { Number ot } \\
\text { sup ractors }\end{array}$ & $\begin{array}{c}\text { Number of } \\
\text { Statements }\end{array}$ \\
Accuracy & 4 & 8 \\
Feasibility & 2 & 5 \\
Utility & 2 & 4 \\
Propriety & 2 & 4 \\
\hline
\end{tabular}




\section{Pilot Study}

The Pilot study was conducted with 30 faculties consisting of 16 males and 14 females. The questionnaire used for the pilot study consisted of 30 items and final validated questionnaire consists of only 21 items. Cronbach's alpha was used as an estimate for the reliability of the instrument during the pilot study. The resulting Cronbach's alpha was 0.8572 which is greater than 0.70 (often used as the lower limit for an acceptable Cronbach's alpha coefficient for a set of items). Thus, the measures of reliability for the instruments were considered acceptable.

\section{Data Analysis Plan}

Following section presents the analysis of the data collected for the study. Data analysis is done with reference to the objectives of the study. Table 1.4 lists various statistical analyses the data is subjected to.

\section{Type of analysis}

Table 1.4: Statistical Analysis Plan

Basic Statistics To describe the characteristic of the frequency, percentage, mean, variance and Standard deviation.

Mann-Whitney U-Test For testing significant differences between two groups i.e. college-wise (public vs private) and gender wise (male and female) variations.

t- Test To test Hypotheses

\section{Data Analysis}

\subsection{Distribution of the sample in terms of Demographic characteristics}

\subsubsection{Gender-wise}

The distribution of the respondents of the study in terms of gender is shown in Table 1.5 and represented in a pictorial form in Figure 1.2 Fifty five percent of the faculties sample $(\mathrm{N}=$ 110) were male and the remaining 45 percent $(N=90)$ were female faculties.

Table 1.5: Gender-wise sample distribution

\begin{tabular}{lll}
\hline Gender & Frequency & Percentage \\
\hline Male & 110 & 55 \\
& 90 & 45
\end{tabular}

\section{Gender wise sample}

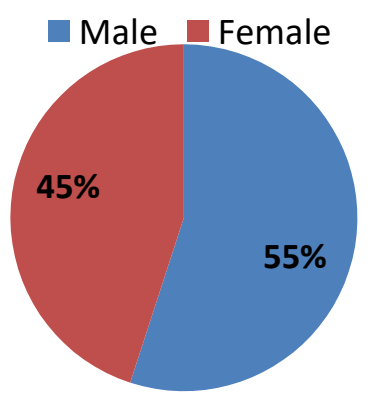

Figure 1.2: Gender-wise sample distribution 


\section{College-wise}

The distribution of the respondents of the study in terms of the type of college in which they work is shown in Table 1.6 and Figure 1.3. Sixty percent of the sample $(N=120)$ were from private colleges. On the other hand, 40 percent $(N=80)$ were from public colleges.

Table 1.6: College-wise sample distribution

\begin{tabular}{lll}
\hline Type of College & Frequency & Percentage \\
\hline Private & 120 & 60 \\
Public & 80 & 40 \\
\hline
\end{tabular}

\section{College-wise sample}

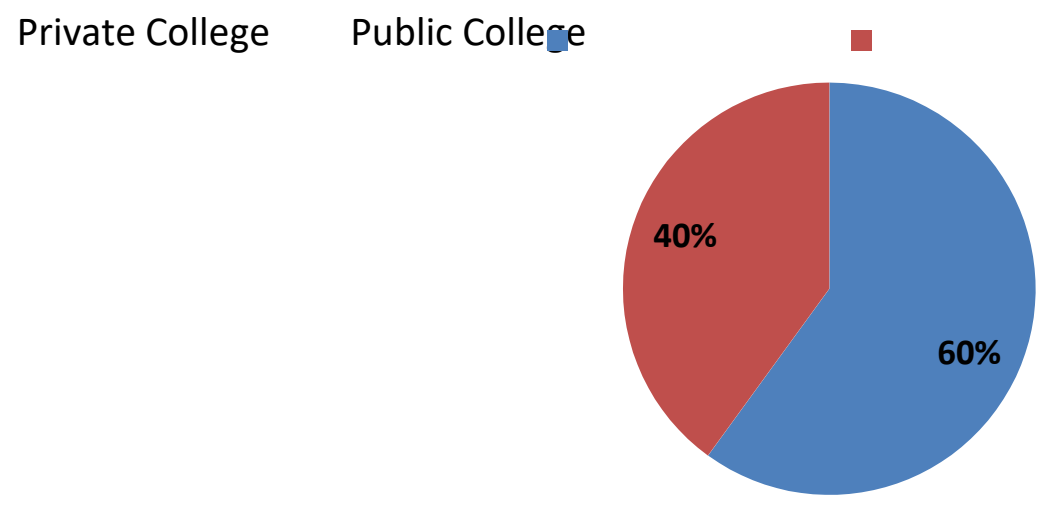

Figure 1.3: College-wise sample distribution

\section{Identification of Parameters of Quality Of LMS}

A team of technical persons from each college assisted in identifying the main parameters of quality and the functional (sub parameters) parameters under each of the main parameters. Factor analysis was done to arrive at the extent of contribution of the quality of functional parameters to the corresponding main parameters. Varimax Rotation method was adopted.

Factor Analysis of Items 1-8 (Accuracy): The results of the factor analysis for items under the accuracy parameter of instrument are given in Table 1.7. Four factors with Eigen values higher than 1.0 were extracted. Factor 1 was able to explain $15.852 \%$ of the total variance, Factor 2 explained $14.716 \%$ of the total variance, Factor 3 explained $13.415 \%$ of the total variance, and Factor 4 explained $11.931 \%$ of the total variance. All the four factors together explained $55.914 \%$ of the total variance. 
Table 1.7: Factor Analysis for Accuracy Items

\begin{tabular}{lll}
\hline Factors of Accuracy & Item in Questionnaire & \% of Variance Explained \\
\hline 1 (content) & 3,6 & 15.852 \\
2 (process) & 2,4 & 14.716 \\
3 (updating) & 1,5 & 13.415 \\
4 (navigation) & 7,8 & 11.931 \\
Total of 4 factors & $1-8$ & 55.914 \\
\hline
\end{tabular}

Factor Analysis of Items 9-13 (Feasibility): The results of the factor analysis for items under the feasibility parameter of instrument are given in Table 1.8. Two factors with Eigen values higher than 1.0 were extracted. Factor 1 was able to explain $28.519 \%$ of the total variance, and Factor 2 explained $23.925 \%$ of the total variance. Both factors together explained $52.444 \%$ of the total variance.

Table 1.8: Factor Analysis for Feasibility Items

\begin{tabular}{|c|c|c|}
\hline Factors of Feasibility & Item in Questionnaire & $\%$ of Variance Explained \\
\hline $\begin{array}{l}1 \text { (effectiveness of } \\
\text { content) }\end{array}$ & $10,12,13$ & 28.519 \\
\hline 2 (application of content) & 9,11 & 23.925 \\
\hline Total of 2 factors & $9-13$ & 52.444 \\
\hline
\end{tabular}

Factor Analysis of Items 14-17 (Utility): The results of the factor analysis for items under the utility parameter of instrument are given in Table 1.9. Two factors with Eigen values higher than 1.0 were extracted. Factor 1 was able to explain $28.919 \%$ of the total variance, and Factor 2 explained $27.873 \%$ of the total variance. Both factors together explained $56.792 \%$ of the total variance.

Table 1.9: Factor Analysis for Utility Items

\begin{tabular}{lll}
\hline Factors of Utility & Item in Questionnaire & \% of Variance Explained \\
\hline 1 (ease of learning) & 14,17 & 28.919 \\
2 (content utility) & 15,16 & 27.873 \\
Total of 2 factors & $14-17$ & 56.792 \\
\hline
\end{tabular}

Factor Analysis of Items 18-21 (Propriety): The results of the factor analysis for items under the propriety parameter of instrument are given in Table 1.10. Two factors with Eigen values higher than 1.0 were extracted. Factor 1 was able to explain $21.423 \%$ of the total variance, and Factor 2 explained $24.937 \%$ of the total variance. Both factors together explained $46.360 \%$ of the total variance.

Table 1.10: Factor Analysis for Propriety Items

\begin{tabular}{lll}
\hline Factors of Propriety & Item in Questionnaire & \% of Variance Explained \\
\hline 1 (organization) & 18,19 & 21.423 \\
2 (error management) & 20,21 & 24.937 \\
Total of 2 factors & $18-21$ & 46.360 \\
\hline
\end{tabular}


Reliability of the items in each of the quality parameter is analyzed for the consistency of the responses by using Cronbach's alpha and item-total correlation. The calculated Cronbach's alpha value for the current study is found to be 0.8572 .

\section{Frequency and Percentage Analysis}

This section presents the descriptive statistics to describe the responses the sample of the study in terms of parameters like Frequency, Percentage, Mean, Standard Deviation etc. The average frequency and percentage of the responses of the faculties for each of the 21 items of the survey instrument are shown in Table 1.11 and Figure 1.4 respectively. The questionnaire was designed using 5-point Likert scale and the range of options for the responses was Strongly Disagree, Disagree, Neutral, Agree and Strongly Agree. For the purpose of analysis, Agree and Strongly Agree are combined into one group as Agree; similarly Disagree and Strongly Disagree are combined into one group as Disagree.

Table 1.11- Average Frequency of Rusponses

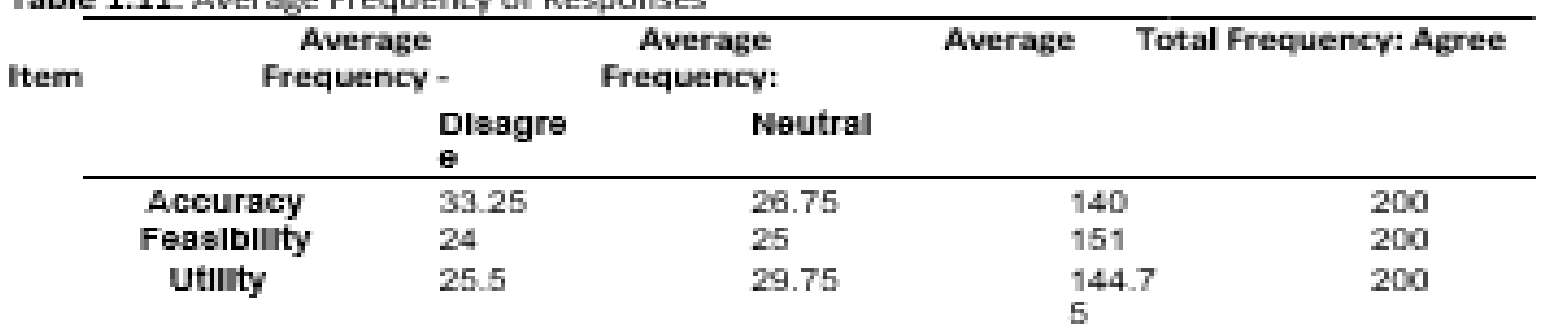

\section{Average Item-wise Response (in percent)}

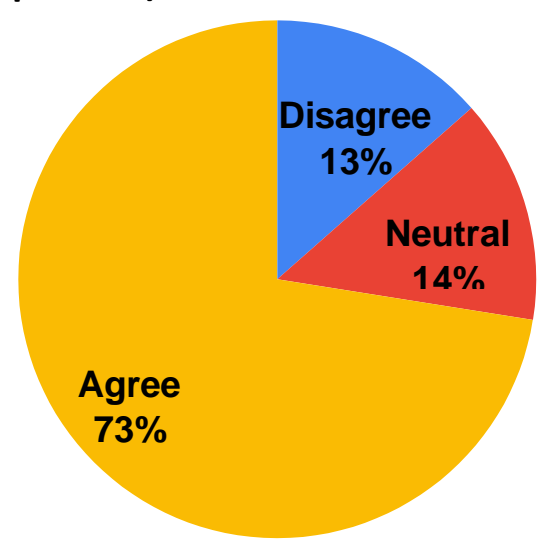

Figure 1.4: Average Item-wise response (in percentage)

\section{Mean and Standard Deviation}

Details of mean and standard deviation of 21 items in the questionnaire are given in Table 1.12. It can be inferred from the table that the item 11 and item 21 has the highest mean score $(M=4.49)$ and item 2 and item 14 , has the least mean scores $(M=3.37)$. The overall mean score of the 21 items was 84.62, the variance 103.734 and standard deviation 10.185. 
Table 1.12: Mean and SD of 21 Items in Questionnaire

\begin{tabular}{llllll}
\hline Item & Mean & SD & Item & Mean & SD \\
\hline 1 & 3.9913 & 0.7995 & 12 & 3.9913 & 0.8102 \\
2 & $\mathbf{3 . 3 7 3 4}$ & 0.7507 & 13 & 4.3921 & 0.6674 \\
3 & 4.3253 & 0.5789 & 14 & $\mathbf{3 . 3 7 3 4}$ & 0.7507 \\
4 & 3.841 & 0.8998 & 15 & 3.8744 & 0.5897 \\
5 & 4.3253 & 0.5803 & 16 & 3.8076 & 0.8113 \\
& & & & & \\
\hline 6 & 3.8577 & 0.7916 & 17 & 4.2919 & 0.7689 \\
7 & 4.2919 & 0.7861 & 18 & 4.3921 & 0.6674 \\
8 & 4.0581 & 0.8106 & 19 & 3.8243 & 0.8018 \\
9 & 3.8577 & 0.8014 & 20 & 3.9579 & 0.8783 \\
10 & 3.8076 & 0.8113 & 21 & $\mathbf{4 . 4 9 2 3}$ & 0.6978 \\
11 & $\mathbf{4 . 4 9 2 3}$ & 0.6978 & & & \\
& & & & &
\end{tabular}

\section{Hypotheses Testing}

Hypothesis $1\left(\mathrm{H}_{01}\right)$ : There is no significant difference between the parameters of quality of LMS and theircorresponding weighted mean score.

The weighted average of the score was calculated in order to evaluate the quality of LMS based on the responses of the faculties. It is presumed that a value of the score greater than or equal to 3.75 out of 5 can be taken as the threshold limit. If the mean score for an item or category of items exceeds the threshold value, it is presumed that the item and categories are measuring appropriately. Since there are 8 items in the scale for measuring accuracy, the expected threshold value for the items of accuracy will be $30(8 \times 3.75)$, the expected threshold value for feasibility has been worked out to be $18.75(5 \times 3.75)$, the expected threshold value for Utility will be $15(4 \times 3.75)$ and finally, the expected threshold value for propriety is $15(4 \times 3.75)$. Finally, the expected threshold value for total score will be 78.75 which is obtained by adding the threshold value of 4 categories $(30+18.75+15+15=78.75)$. The expected threshold value for each variable of the scale is shown in Table 1.13.

Table 1.13: Threshold values of parameters of quality

\begin{tabular}{lll}
\hline Items in Questionnaire & Threshold Value & Mean Value $(\mathbf{N}=\mathbf{2 0 0})$ \\
\hline Accuracy $(1-8)$ & 30 & 32.06 \\
Feasibility $(9-13)$ & 18.75 & 20.54 \\
Utility $(14-17)$ & 15 & 15.35 \\
Propriety $(18-21)$ & 15 & 16.67 \\
Total (21 items) & 78.75 & 84.62 \\
\hline
\end{tabular}

From Table 1.13 it can be inferred that the values of each of the parameters of quality are greater than their corresponding threshold values. This indicates that the quality of the learning management systems is in the acceptable level and the LMS needs no modification. One-sample t-test was conducted to test the significance of difference between the values of various parameters of quality and their corresponding threshold values. The values of the 
various parameters of quality are presented in Table 1.14. It can be inferred that the $p$-values for all the parameters are below the cut-off value of 0.05 .

Table 1.14 One -Sample t-test to test hypothesis

\begin{tabular}{cccccc}
\multirow{2}{*}{ Items } & \multicolumn{2}{c}{ Sample $(\mathbf{N}=\mathbf{2 0 0})$} & t-value & DF & p-value \\
\cline { 2 - 3 } & Mean & SD & & & \\
\hline Accuracy & 32.06 & 3.61 & 15.178 & 199 & 0.000 \\
Feasibility & 20.54 & 3.12 & 9.674 & 199 & 0.000 \\
Utility & 15.35 & 2.3 & 5.893 & 199 & 0.000 \\
Propriety & 16.67 & 2.92 & 3.016 & 199 & 0.000 \\
Total & 84.62 & 10.185 & 8.975 & 199 & 0.016
\end{tabular}

Hence the null hypothesis is accepted for all the parameters of quality of LMS.

Hypothesis $2\left(\mathrm{H}_{02}\right)$ : There is no significant difference in the responses of male and female faculties withrespect to the parameters of quality of LMS.

Table 1.15 shows the details of the analyses of the male and female faculties with respect to quality parameters of LMS.

Table 1.15 Gender-wise responses

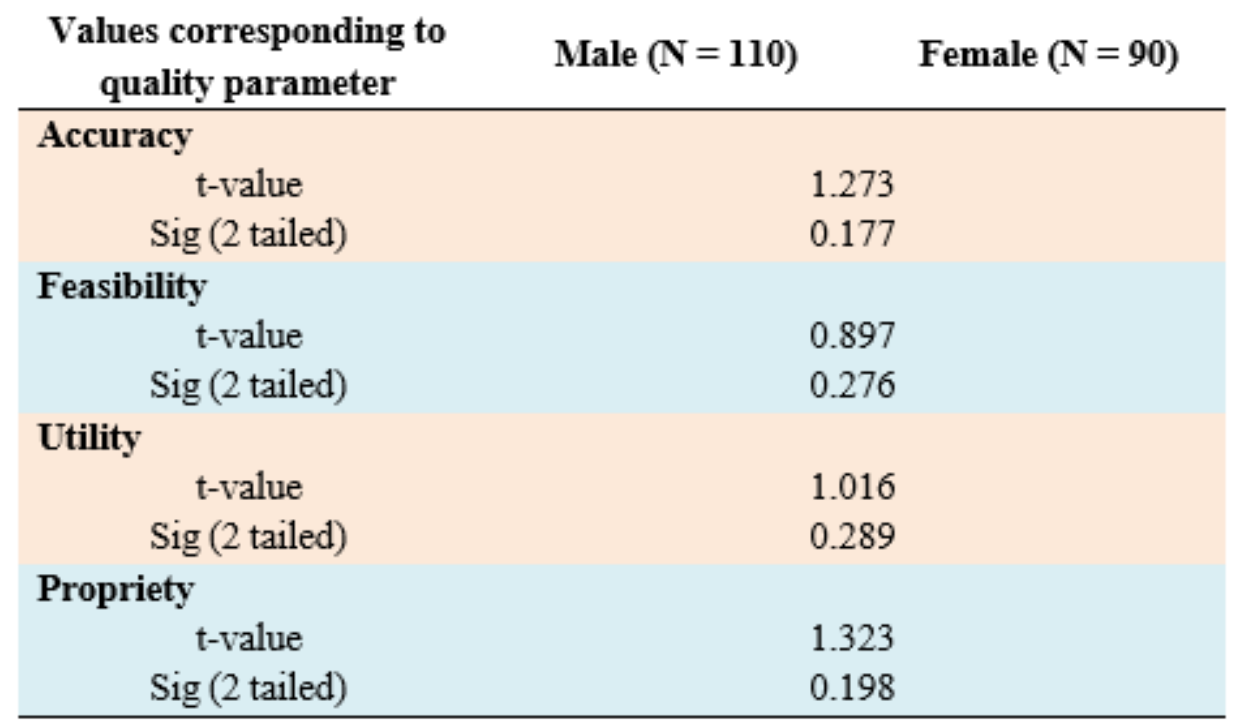

Since the significant value 0.177 is higher than 0.01 at 0.05 level, the hypothesis that there is no significant difference in the responses of male and female faculties with respect to accuracy is accepted. Since the significant value 0.276 is higher than 0.01 at 0.05 level, the hypothesis that there is no significant difference in the responses of male and female faculties with respect to feasibility is accepted. Significant values of 0.289 and 0.198 for utility and propriety respectively are greater than 0.01 at 0.05 level, the hypotheses that there is no significant difference in the responses of male and female faculties with respect to utility and propriety is accepted. Hence the null hypothesis is accepted. 
Hypothesis $3\left(\mathrm{H}_{03}\right)$ : There is no significant difference in the responses of faculties working at public andprivate colleges with respect to quality parameters of LMS.

Table 1.16 shows the details of the analyses of the private and public college faculties with respect to quality parameters of LMS.

Table 1.16: College-wise responses with respect to quality parameters

\begin{tabular}{ccc}
$\begin{array}{l}\text { Values corresponding to } \\
\text { quality parameter }\end{array}$ & $\begin{array}{c}\text { Private Colleges } \\
(\mathbf{N}=\mathbf{1 2 0})\end{array}$ & $\begin{array}{c}\text { Public Colleges } \\
(\mathbf{N}=\mathbf{8 0})\end{array}$ \\
\hline Accuracy & 1.015 \\
t-value & 0.298 \\
Sig (2 tailed) & \\
Feasibility & 0.397 \\
t-value & 0.713 \\
Sig (2 tailed) & \\
Utility t-value $\quad 0.924$ \\
Sig (2 tailed) \\
Propriety \\
\hline
\end{tabular}

Since the significant value 0.298 is higher than 0.01 at 0.05 level, the hypothesis that there is no significant difference in the responses of private and public college faculties with respect to accuracy is accepted. Since the significant value 0.713 is higher than 0.01 at 0.05 level, the hypothesis that there is no significant difference in the responses of private and public college faculties with respect to feasibility is accepted. Significant values of 0.376 and 0.856 for utility and propriety respectively are greater than 0.01 at 0.05 level, the hypotheses that there is no significant difference in the responses of private and public college faculties with respect to utility and propriety is accepted. Hence the null hypothesis is accepted.

\section{Mann-Whitney $U$ test to test the significance of difference between the samples in terms} of their gender

Gender wise differences in the perception and evaluation of the different items of the questionnaire are presented in Table 1.17. The mean scores obtained from male and female respondents and their statistical significance are tested using Mann-Whitney ' $U$ ' test. 


\begin{tabular}{|c|c|c|c|c|}
\hline \multirow{2}{*}{$\begin{array}{l}\text { Mean } \\
\text { Item }\end{array}$} & \multicolumn{2}{|c|}{ Mean Female } & \multicolumn{2}{|l|}{ Mann- } \\
\hline & $\begin{array}{l}\text { Male } \\
(N=110)\end{array}$ & $(N=90)$ & Whitney $U$ & p-value \\
\hline 1 & 4.0748 & 3.7575 & 23751.200 & 0.02 \\
\hline 2 & 3.3567 & 3.4068 & 26248.200 & 0.613 \\
\hline 3 & 4.7094 & 4.6092 & 26074.200 & 0.398 \\
\hline 4 & 3.8076 & 3.9078 & 26288.200 & 0.605 \\
\hline 5 & 4.5758 & 4.4923 & 25971.200 & 0.376 \\
\hline 6 & 3.8744 & 3.841 & 26606.000 & 0.774 \\
\hline 7 & 4.2418 & 4.4088 & 25368.200 & 0.189 \\
\hline 8 & 4.1416 & 3.7909 & 24029.200 & 0.026 \\
\hline 9 & 3.8744 & 3.8243 & 26373.000 & 0.662 \\
\hline 10 & 3.7575 & 3.8911 & 25768.200 & 0.391 \\
\hline 11 & 4.5424 & 4.3921 & 25539.000 & 0.187 \\
\hline 12 & 4.1249 & 3.6573 & 23206.000 & 0.005 \\
\hline 13 & 4.4589 & 4.2251 & 25154.200 & 0.151 \\
\hline 14 & 3.6072 & 3.9913 & 23365.000 & 0.013 \\
\hline 15 & 3.8911 & 3.841 & 26409.200 & 0.67 \\
\hline 16 & 3.7575 & 3.8911 & 25768.200 & 0.391 \\
\hline 17 & 4.2418 & 4.4088 & 25368.200 & 0.189 \\
\hline 18 & 4.4589 & 4.2251 & 25154.200 & 0.151 \\
\hline 19 & 3.841 & 3.7742 & 26192.000 & 0.58 \\
\hline 20 & 4.008 & 3.8243 & 25168.000 & 0.195 \\
\hline 21 & 4.5424 & 4.3921 & 25539.000 & 0.187 \\
\hline
\end{tabular}

Items 1 (accuracy), 8 (accuracy), 12 (feasibility), and 13 (utility) have $p$-values lesser than 0.05 , hence the difference between male and female responses in these cases are statistically significant. The quality parameter "propriety" does not get influenced by gender.

\section{Mann-Whitney $U$ test to test the significance of difference between the samples in terms} of their college type (private or public)

The means of item scores with regard to the respondents from private and public colleges are compared in Table 1.18 and the significant differences, if any, between them are tested.

Table 1.18: Mann-Whitney U Test with College Type as Independent Variable

\begin{tabular}{|c|c|c|c|c|}
\hline \multirow[b]{2}{*}{ Item } & \multirow{2}{*}{$\begin{array}{l}\text { Mean } \\
\text { Private College } \\
(\mathrm{N}=120)\end{array}$} & \multicolumn{3}{|c|}{ Mean Mann-Whitney } \\
\hline & & $\begin{array}{l}\text { Public College } \\
(\mathrm{N}=\mathbf{8 0})\end{array}$ & $\mathbf{U}$ & \\
\hline 1 & 4.1082 & 3.6907 & 24454.000 & 0.003 \\
\hline 2 & 3.3901 & 3.3233 & 27886.000 & 0.570 \\
\hline 3 & 4.6092 & 4.8263 & 24221.000 & 0.000 \\
\hline 4 & 3.9245 & 3.6573 & 26248.200 & 0.078 \\
\hline 5 & 4.6259 & 4.3754 & 23960.000 & 0.000 \\
\hline 6 & 3.841 & 3.9245 & 27705.000 & 0.478 \\
\hline 7 & 4.342 & 4.1583 & 26109.000 & 0.037 \\
\hline 8 & 4.0581 & 4.0581 & 28099.000 & 0.631 \\
\hline 9 & 3.8076 & 3.9913 & 26489.000 & 0.132 \\
\hline 10 & 3.8577 & 3.674 & 27405.000 & 0.360 \\
\hline 11 & 4.4422 & 4.6259 & 28077.200 & 0.558 \\
\hline 12 & 3.8577 & 4.3253 & 24013.200 & 0.001 \\
\hline 13 & 4.4255 & 4.3086 & 27892.200 & 0.515 \\
\hline 14 & 3.8243 & 3.4402 & 24627.200 & 0.005 \\
\hline 15 & 3.8577 & 3.9245 & 26928.000 & 0.208 \\
\hline 16 & 3.8577 & 3.674 & 27405.000 & 0.360 \\
\hline 17 & 4.342 & 4.1583 & 26109.000 & 0.037 \\
\hline 18 & 4.4255 & 4.3086 & 26489.000 & 0.132 \\
\hline 19 & 3.8076 & 3.8577 & 27405.000 & 0.360 \\
\hline 20 & 3.8577 & 4.1583 & 28077.200 & 0.558 \\
\hline 21 & 4.4422 & 4.6259 & 24013.200 & 0.001 \\
\hline
\end{tabular}


Items 1, 3, 5, and 7 belonging to accuracy factor of quality, item 12 (feasibility), items 14, 17 belonging to utility category and item 21 (propriety) have $p$-values lesser than 0.05 , hence the difference in responses between private and public college faculties in these cases are statistically significant.

\section{Findings and Conclusions}

The results of the study showed that the parameters of quality are highly effective for evaluating the quality of learning management systems from the faculties' point of view.

The effectiveness of the learning management systems is due to the fact that it consists of quality characteristics that are relevant for faculty development program.

The results showed that all these factors have substantial and statistically significant influences on the outcome of the responses to the items in the questionnaire.

The values of the parameters of quality of LMS namely accuracy, feasibility, utility and propriety are higher than their corresponding threshold values. Hence the quality parameters are acceptable.

Regarding difference in the responses of male and female faculties with respect to quality parameters, the findings indicate that the quality parameter namely 'propriety' does not get influenced by gender.

\section{Recommendations}

Faculty members should consider the content requirements of the user, modes of presentation, feedback mechanism and interactive features in addition to the quality parameters to make learning more effective.

Colleges have to encourage faculties in the use of learning management systems for upskilling as a part of faculty development program.

Users of LMS should provide constructive feedback with their experience of using learning management system to the trainers, LMS developers to enable them to make suitable decisions in modifying the system as per the user requirements.

Other quality parameters and their corresponding functional parameters may be identified and used in the design and development of the learning management systems in future.

Quality evaluation should be done in each stage of LMS development by taking into consideration the users' need.

\section{Acknowledgement}

The authors would like to express gratitude to Global Academics Research Academy (GARA) for overall support.

\section{Corresponding Author}

Prof. Dr. Asif Mahbub Karim

Dean, Binary Graduate School, Binary University, Malaysia

Email: drasifmkarim@gmail.com 


\section{References}

Alshams, Y. A. A. B., Adaikalam, J., Karim, A. M., Hock, O. Y., \& Hossain, M. I. (2020). Application of Strategic Management Information System (SMIS) in the Ministry of Interior, UAE: Issues and Challenges. International Journal of Academic Research in Business and Social Sciences, 10(2), 346-361.

Bashir, M. A., Ali, M. H., Wai, L. M., Hossain, M. I., \& Rahaman, M. S. (2020). Mediating Effect of Customer Perceived Value on the Relationship between Service Quality and Customer Satisfaction of E-Banking in Bangladesh. International Journal of Advanced Science and Technology. Vol. 29, No. 2, pp. $3590-3606$

Balogh, Zoltan \& Turčáni, Milan. (2011). Possibilities of modelling web-based education using IF-THEN rules and fuzzy petri nets in LMS. Communications in Computer and Information Science. 251. 93-106. 10.1007/978-3-642-25327-0_9.

Bhattacharjee, A., Jahanshahi, A. A., Polas, M. R. H., Hossain, M. I., \& Asheq, A. S. (2019). Customer Care Service Management is Moving Forward to Achieve Sustainable Customer Retention in Every Industry. Does it play a Role to Increase Brand Retention? International Journal of Management and Sustainability, 8(2), 88-97.

Cavus, N., Uzunboylu, H., and Ibrahim, D. (2007). Assessing the Success Rate of Students Using a Learning Management System Together with a Collaborative Tool in WebBased Teaching of Programming Languages, Journal of Educational Computing Research, 36(3), pp. 301-321. doi: 10.2190/T728-G676- 4N18-6871.

Cavus, N. (2008). Education technologies of the information age: course management systems. Extend 28(2)

Chang, C. L. (2008). Faculty Perceptions and Utilization of a Learning Management System in Higher Education. Unpublished doctoral dissertation, Ohio University, USA.

Chiu, Ch., Hsu, M., Sun, S., Lin, T., Sun, P. (2005). Usability, quality, value and e-learning continuance decisions, Computers \& Education, 45 (2005), 399-416.

Cynthia, Gautreau. (2011). Motivational Factors Affecting the Integration of a Learning Management System by Faculty. Journal of Educators Online. 8. 10.9743/JEO.2011.1.2.

Ellis, R. K. (2009). Field guide to learning management systems. ASTD Learning Circuits

Fard, K., Tafreshi, F., Nilashi, M., \& Jalalyazdi, M. (2014). Assessing the critical factors for elearning systems using fuzzy TOPSIS and fuzzy logic. International Journal of Computers \& Technology, 12(6), 3546- 3561.

Ghilay, Yaron. (2019). Effectiveness of Learning Management Systems in Higher Education: Views of Lecturers with Different Levels of Activity in LMSs. 3. 29-50.

Gilhooly, K. (2001). Making e-learning effective. Computerworld, 35(29), 52-53

Hossain, M. I., Polas, M. R. H., Rahman, M. M., Islam, T., \& Jamadar, Y. (2020). An Exploration of COVID-19 Pandemic and its Consequences on FMCG Industry in Bangladesh. Journal of Management Info, 7(3), 145-155.

https://doi.org/10.31580/jmi.v7i3.1484

Hossain, M. I., Yagamaran, K. S. A., Afrin, T., Limon, N., Nasiruzzaman, M., \& Karim, A. M. (2018). Factors influencing unemployment among fresh graduates: $A$ case study in Klang Valley, Malaysia. International Journal of Academic Research in Business and Social Sciences, 8(9), 1494-1507.

Jayakumar, R., \& Banbehari, M. (2014). Website quality assessment model for developing efficient e- learning framework- a novel approach. International Journal of Engineering and Technology, 5(5), 3770-3780. 
Klobas, J., \& McGill, T. (2010). The role of involvement in learning management system success. J. Computing in Higher Education. 22. 114-134. 10.1007/s12528-010-9032-5.

Basak, K. S., Wotto, M., \& Belanger, P. (2018). E-learning, M-learning and D-learning: Conceptual definition and comparative analysis. E-Learning and Digital Media, 15(4), 191-216.

Liaw, Sh., Huang, H., Chen, G. (2007). Surveying instructor and learner attitudes toward elearning, Computer and Education, 49 (2007), 1066-1080.

Little-Wiles, J. M., Hundley, S., Worley, W. L., \& Bauer, E. (2012). Faculty perceptions and use of a learning management system at an urban, research institution. American Society for Engineering Education. Proceedings from 119th ASEE 2012 Conference. San Antonio, TX.

Lonn, Steven \& Teasley, Stephanie. (2009). Saving time or innovating practice: Investigating perceptions and uses of Learning Management Systems. Computers \& Education. 53. 686-694. 10.1016/j.compedu.2009.04.008.

Morgan, G. (2003). Faculty use of course management systems in the University of Wisconsin System. EDUCAUSE Center for Applied Research Report.

Mustafa, M. (2013). The impact of system quality in e-learning system. Journal of Computer Science and Information Technology, 1(2), 14-23.

Nadire Cavus. (2015). Distance Learning and Learning Management Systems, Procedia - Social and Behavioral Sciences, Volume 191, Pages 872-877, ISSN 1877-0428.

Polas, M. R. H., Bhattacharjee, A., Raju, V., Hossain, M. I. (2019). Demographic Factors Influence on the Tendency to Become Entrepreneur: Estimating the Antecedents and Consequences of Entrepreneurial Tendency. International Journal of Management and Sustainability. 8(1), 48-60

Polas, M. R. H., Juman, M. K., Karim, A. M., Tabash, M. I., Hossain, M. I. (2020). Do Service Quality Dimensions Increase the Customer Brand Relationship among Gen Z? The Mediation Role of Customer Perception between the Service Quality Dimensions (SERVQUAL) and Brand Satisfaction. International Journal of Advanced Science and Technology. 29(4), 1050-1070

Ruiz, J. G., Mintzer, M. J., Leipzig, R. M. (2006). The Impact of E-Learning in Medical Education, Academic Medicine, Vol. 81, No. 3 / March 2006.

Rodrigues, H., Almeida, F., Figueiredo, V., \& Lopes, S. L. (2019). Tracking e-learning through published papers: A systematic review. Computers \& Education, 136, 87-98. 